\title{
ANALISIS KANDUNGAN KIMIA ASAP CAIR DARI TEMPURUNG DAN SABUT KELAPA DENGAN METODE DESTILASI
}

(Analysis of liquid smoke chemical content from tempurung and coconut shell with destilation method)

\author{
Ria Megasari \\ Universitas Ichsan Gorontalo, Program Studi Agroteknologi \\ JL. Drs. Achmad Nadjamuddin, Biyawao, Kota Selatan, Dulalowo Timur, \\ Kota Tengah, Kota Gorontalo, Gorontalo 96138 \\ Email: elfaega406@gmail.com
}

\begin{abstract}
ABSTRAK
Tujuan dari penelitian ini adalah untuk mengetahui kandungan asap cair dari tempurung kelapa dan sabut kelapa dengan metode destilasi. Hasil penelitian ini diharapkan diharapkan dengan pemanfaatan limbah kelapa seperti tempurung kelapa yang diolah menjadi asap cair mampu memberi nilai tambah bagi kelompok tani, pengusaha, maupun stakeholder lainnya dan berkontribusi terhadap bioindustri pertanian. Penelitian ini dilaksanakan pada bulan Maret sampai bulan Juni 2020 di Laboratorium Fisika FMIPA Universitas Negeri Gorontalo. Kegiatan penelitian meliputi pembuatan asap cair dan pemurnian asap cair. Sesuai dengan hasil analisi data dari penelitian yang telah dilakukan diperoleh kesimpulan bahwa Hasil analisis kandungan kimia dari asap cair tempurung kelapa memiliki berat jenis $1,083 \mathrm{gr} / \mathrm{cm}^{3}$, keasaman 2,29, kadar asam sebesar 4,628\% dan kadar fenol 2,432\%. Berbeda dengan kandungan kimia dari asap cair sabut kelapa yaitu berat jenis $1,009 \mathrm{gr} / \mathrm{cm}^{3}$, keasaman 2,25, kadar asam sebesar 3,562\% dan kadar fenol 2,387\%. Hasil analisis kandungan kimia dari asap cair yang dihasilkan bekum sepenuhnya masuk dalam kategori asap cair standar Jepang.
\end{abstract}

Kata Kunci : Tempurung kelapa; sabut kelapa; destilasi; asap cair

\begin{abstract}
The study aimed to study liquids' collection from coconut shells and coconut coir by the distillation method. Expected research results by utilizing coconut as a coconut shell that is processed into liquid add value to farmer groups, entrepreneurs, and other stakeholders and contributes to the agricultural bioindustry. This research was conducted from March to June 2020 in the Physics Laboratory, Faculty of Mathematics and Natural Sciences, State University of Gorontalo. Research activities include making liquid and instant liquid. By following the results of data analysis from the research done, it is concluded that the results of chemical reserve analysis of liquid coconut shells have a weight type of $1.083 \mathrm{gr} / \mathrm{cm}^{3}$, the acidity of 2.29 , the acid content of $4.628 \%$, and phenol content of $2.432 \%$. In contrast to instant coconut fiber's chemical content, which is specific gravity $1,009 \mathrm{gr} / \mathrm{cm}^{3}$, acidity 2,25 , acid content of $3,562 \%$ and phenol content of $2,387 \%$. The chemical content of liquid produced by liquid falls into the Japanese standard liquid smoke category.
\end{abstract}

Keywords : Coconut shell; coconut fiber; distillation; liquid smoke

\section{PENDAHULUAN}

Asap cair merupakan asam cuka (vinegar) yang diperoleh dengan cara distilasi kering bahan baku pengasap seperti kayu, lalu diikuti dengan peristiwa kondensasi dalam kondensor berpendingin 
air. Asap cair berasal dari bahan alami yaitu pembakaran hemiselulosa, selulosa, dan lignin dari kayu-kayu keras sehingga menghasilkan senyawa-senyawa yang memiliki efek antimikroba, antibakteri, dan antioksidan seperti senyawa asam dan turunannya, alkohol, fenol, aldehid, karbonil, keton dan piridin, sehingga banyak diaplikasikan sebagai pengawet alami pada makanan serta memberikan karakteristik sensori berupa aroma, warna, serta rasa yang khas pada produk pangan (Budijanto dkk., 2008), sebagai anti bakteri yang dapat menghambat aktivitas pertumbuhan $S$. aureus, $P$. aeruginosa, E. coli and C. albican (Zuraida et al., 2011; Kailaku et al., 2017). Penggunaan asap cair juga disesuaikan dengan klasifikasi kualitas asap cair yang terdiri dari 3 grade. Grade C (grade 3) digunakan sebagai pengawet kayu dan koagulan, grade $\mathrm{B}$ (grade 2) digunakan sebagai antimikroba dan grade A (grade 1) digunakan sebagai pengawet alami makanan (Kailaku et al., 2017).

Prospek penggunaan asap cair sangat luas, mencakup industri makanan sebagai pengawet, industri kesehatan, pupuk tanaman, bioinsektisida, pestisida desinfektan, herbisida, dan lain sebagainya. Prospek penggunaan asap cair yang sangat luas ini memiliki berbagai keunggulan bila dibandingkan dengan penggunaan bahan kimia sintetik. Asap 62 cair lebih mudah diaplikasikan karena konsentrasi asap cair dapat dikontrol agar memberi flavor dan warna yang sama dan seragam. Asap cair telah disetujui oleh banyak negara untuk digunakan pada bahan pangan. Bahan ini dapat diproduksi secara sederhana dengan menggunakan bahan dan peralatan yang mudah diperoleh serta relatif murah.

Kualitas dan kuantitas unsur kimia asap umumnya tergantung pada jenis bahan pengasap yang digunakan. Bahan baku yang umum digunakan adalah bahan yang mengandung selulosa, hemiselulosa, dan lignin. Selama ini bahan kayu keras seperti kayu jati (Firmansyah, 2004), mangium, tusam (Nurhayati, 2000), dan sengon banyak digunakan sebagai bahan pembuatan asap cair. Kedua jenis kayu tersebut digunakan dalam bentuk blok kayu ataupun serbuk kayu yang dipres. Namun, harga kayu yang mahal dan ketersediaannya yang terbatas menyebabkan biaya produksi pembuatan asap cair menjadi tinggi.

Adanya kendala penggunaan bahan pengasap dari kayu tersebut mendorong penggunaan bahan pengasap dari jenis lain, seperti tempurung dan sabut kelapa. Tempurung kelapa adalah inti buah dan terletak di bagian sebelah dalam sabut dengan ketebalan berkisar 3-6 mm (Fikri, $d k k$. 2018). Bahan ini masih memiliki komponen selulosa, hemiselulosa, dan 
lignin yang cukup besar. Selain itu, penggunaan limbah kelapa ini dapatmemberikan nilai tambah lain sebagai asap cair dibandingkan dengan penggunaannya sebagai keset, anyaman, atau suvenir.

Tempurung kelapa merupakan limbah pertanian yang belum termanfaatkan secara optimal, hanya sebagian kecil yang diolah menjadi media tanam dan arang aktif. Pada prinsipnya teknologi pembuatan asap cair dari tempurung kelapa cukup sederhana, yakni teknologi pirolisis (pembakaran untuk menghasilkan asap) dan teknologi kondensasi (pengembunan asap menjadi cair). Alat pembakarannya pun sangat mudah diperoleh karena dapat menggunakan drum bekas. Yang perlu diperhatikan adalah teknik untuk mempertahankan agar proses pembakaran tetap berlangsung hingga tempurung terbakar habis. Berdasarkan latar belakang ini sehingga perlu dilakukan penelitian ini dengan tujuan untuk mengetahui kandungan asap cair dari tempurung dan sabut kelapa dengan metode destilasi

\section{METODE PENELITIAN}

\section{Waktu dan Lokasi Penelitian}

Penelitian ini dilaksanakan pada bulan Maret sampai bulan Juni 2020 di Laboratorium Fisika FMIPA Universitas Negeri Gorontalo.

\section{Bahan dan Alat}

Bahan yang digunakan pada penelitian ini adalah tempurung dan sabut kelapa yang didapat dari penjual kelapa parut di daerah Isimu. Tempurung kelapa dibersihkan permukaannya dari sabut dan dipecah dengan menggunakan golok sampai diameter 5-8 cm, sedangkan sabut dan serbuk kelapa dipisahkan dari jaringannya dengan menggunakan tangan. Untuk bahan analisis digunakan etanol $95 \%$, akuades, reagen Folin-Ciocalteu, asam tanat $0,2 \%, \mathrm{Na}_{2} \mathrm{~S}_{2} \mathrm{O}_{3} 5 \%, \mathrm{Na}_{2} \mathrm{CO}_{3}$ $5 \%$, indikator fenolphthalein, dan $\mathrm{NaOH}$ 0,1 N. Peralatan yang digunakan adalah pembuat arang, labu leher tiga, kondensor, selang, bunsen, golok, termometer, $\mathrm{pH}$ meter, erlenmeyer, gelas piala, tabung reaksi, buret, pipet tetes, labu ukur, vortex shaker, sentrifuse, spektrofotometer, piknometer, dan GC-MS.

\section{Metode Penelitian}

Adapun metodologi pelaksanaan penelitian ini terdiri dari beberapa tahap, yaitu :

\section{Pembuatan Asap Cair}

Sebelum dibakar, bahan baku dibersihkan terlebih dahulu. Tempurung kelapa dibersihkan untuk menghilangkan sabut dari permukaannya. Setelah itu, tempurung kelapa dipotong-potong sampai berukuran diameter kira-kira 5-6 cm, sedangkan sabut dilepaskan serat-seratnya agar mudah dimasukkan ke dalam alat pembakar.. Pengukuran kadar air 
dilakukan pada bahan setiap bahan baku sebelum dibakar. Pembuatan asap cair dilakukan dengan menggunakan kiln yang terbuat dari baja tahan karat yang dilengkapi dengan alat pemanas listrik, tiga kondensor dan dua buah labu penampung destilat. Setiap kali pembakaran, kiln dapat memuat 2000 2500 gram tempurung kelapa atau 500 gram sabut kelapa. Suhu pengolahan diukur dengan thermokopel yang dipasang pada bagian tengah kiln. Suhu yang digunakan adalah $300{ }^{\circ} \mathrm{C}$ dan $500{ }^{\circ} \mathrm{C}$ untuk masing-masing bahan dengan pemanasan selama 5 jam. Cairan yang terbentuk mengalir melalui bagian bawah kiln ke alat pendingin, kemudian destilat ditampung dalam 2 buah labu dengan volume 2 liter. Destilat dikumpulkan dalam labu pemisah, dikocok dan dibiarkan 24 jam untuk mengendapkan ter. Bagian atas larutan destilat adalah pyroligneous liquor sedangkan bagian bawah adalah endapan ter (settled ter).

\section{Pemurnian Asap Cair}

Pemurnian asap cair dilakukan dengan cara distilasi. Asap cair dimasukkan sebanyak $200 \mathrm{ml}$ ke dalam labu distilasi, dipanaskan menggunakan pemanas listrik. Proses distilasi ini dilakukan untuk mengambil seluruh fraksi dan diatur pada berbagai suhu dan dilakukan hingga suhu maksimum, yaitu $200^{\circ} \mathrm{C}$. Suhu yang ditera adalah suhu asap cair dalam labu distilasi. Uap yang terbentuk lalu masuk ke dalam pipa pendingin balik (condensor) dan destilat ditampung dalam sebuah wadah atau labu.

\section{Parameter Pengamatan}

Rendemen

$\mathrm{pH}$

Berat jenis

Warna

Transparansi

Kadar Asam

\section{HASIL DAN PEMBAHASAN}

\section{Rendemen Asap Cair}

Dari proses pirolisis diperoleh asap cair sebagai distilat dan arang sebagai residu. Rendemen asap cair yang dihasilkan dari tempurung kelapa dan sabut kelapa dapat dilihat pada tabel 1 . Asap cair yang dihasilkan lebih banyak dari sampel sabut kelapa dibandingkan yang dihasilkan dari tempurung kelapa. Hal ini disebabkan karena adanya perbedaan senyawa yang berasal dari kedua sampel tersebut, misalnya kandungan lignin, hemiselulosa, selulosa dan air. 
Tabel 1. Data rendemen asap cair hasil pirolisis tempurung kelapa dan sabut kelapa

\begin{tabular}{cc}
\hline Sampel & Rendemen Asap Cair $(\% \mathrm{~b} / \mathrm{b})$ \\
\hline Tempurung Kelapa & 42 \\
Sabut Kelapa & 32,4 \\
\hline Sumber : Data Primer Hasil Penelitian 2020.
\end{tabular}

Rendemen asap cair yang dihasilkan

pada proses pirolisis tempurung kelapa lebih tinggi dibandingkan asap cair ampas tebu yaitu 42 dan 32,4 gram. Hal ini disebabkan karena tempurung kelapa mengandung lebih banyak lignin dibandingkan sabut kelapa sehingga asap cair yang dihasilkan lebih banyak. Hal ini sesuai dengan pernyataan Rasyidta dan Pari (2015) bahwa kayu keras termasuk tempurung kelapa banyak digunakan untuk memproduksi asap cair karena komposisi kayu keras yang terdiri dari lignin, selulosa, dan metoksil memberikan sifat organoleptik yang baik. Selain itu, Kadir et al (2010) menjelaskan bahwa hasil analisis komponen kimiawi tempurung kelapa hibrida menunjukkan bahwa kandungan lignin sebesar 36,50\%. Sedangkan hasil analisis komponen kimiawi sabut kelapa menunjukkan bahwa kandungna lignin yaitu 29,5\% (Wardhani, 2004).

"Rendemen asap cair juga dapat dipengaruhi oleh kadar abu dari sampel tersebut. Semakin berkurangnya kadar abu yang terjadi pada perlakuan tempurung kelapa dan sabut kelapa juga mempengaruhi nilai rendemen yang diperoleh. Semakin rendah kadar abu, maka akan semakin tinggi nilai rendemennya. Menurut Kasmudjo (2012) dikatakan bahwa tinggi rendahnya rendemen dalam produksi karbonisasi dipengaruhi beberapa factor antara lain iklim, musim, unsur tanaman, keadaan tanah, bahan baku, dan cara pembakaran.

\section{Kandungan Kimia Asap Cair}

Standar kualitas asap cair yang dipakai yaitu berdasarkan standar kualitas Jepang dikarenakan belum adanya standar kualitas asap cair dari Indonesia, sehingga produksi asap cair yang akan dipasarkan ke Jepang harus memenuhi spesifikasi yang telah ditentukan. Hasil pengujian kualitas asap cair tempurung kelapa dan sabut kelapa yang dibandingkan dengan standar kualitas asap cair asal Jepang, memiliki perbedaan yang signifikan dan dapat dilihat pada Tabel 2 . 
Tabel 2. Hasil pengujian kualitas asap cair dibandingan dengan standar kulit asap cair asal Jepang

\begin{tabular}{cccc}
\hline Parameter & Tempurung Kelapa & Sabut Kelapa & Standar Kualitas Jepang \\
\hline Berat Jenis & 1,083 & 1,009 & $<1,005$ \\
$\left(\mathrm{gr} / \mathrm{cm}^{3}\right)$ & 2,29 & 2,25 & $1,5-3,7$ \\
Keasaman $(\mathrm{pH})$ & 4,628 & 3,562 & $1-18 \%$ \\
Kadar Asam $(\%)$ & 2,432 & 2,387 & - \\
Kadar Fenol (\%) & &
\end{tabular}

Sumber : Data Primer Hasil Penelitian, 2020.

\section{Berat Jenis}

Berat jenis asap cair diperoleh dengan perhitungan massa/volume, dimana masa adalah berat asap cair yang diperoleh dengan satuan gram dengan massa satuan Newton dan volumenya dalam satuan $\mathrm{ml}$.

Berat jenis asap cair dari tempurung kelapa $1,083 \mathrm{gr} / \mathrm{cm}^{3}$, sedangkan berat jenis pada sabut kelapa sebesar 1,009 $\mathrm{gr} / \mathrm{cm}^{3}$. Jumlah berat jenis asap cair ini jauh lebih besar diabndingkan berat jenis asap cair standar jepang. Berat jenis asap cair yang diperoleh dari hasil penelitian menunjukkan kandungan ter yang masih tinggi. Yatagai (2001) mengatakan jika nilai berat jenis yang diukur melebihi cakupan standar kualitas asap cair asap cair asal Jepang, menandakan adanya kandungan ter yang masih tinggi. Hal ini menandakan perlunya proses penyulingan yang lebih baik.

pH

Nilai $\mathrm{pH}$ yang rendah menunjukan kualitas asap cair yang dihasilkan memiliki kualitas yang tinggi, karena berpengaruh terhadap nilai awet daya simpan produk atau sifat organoleptiknya. Karena pada
$\mathrm{pH}$ yang rendah mikroba atau bakteri merugikan tidak dapat hidup dan berkembang biak dengan baik. Hal ini sesuai dengan pernyataan Nasir et al (2008) bahwa senyawa-senyawa asam mempunyai peranan sebagai antibakteri dan membentuk citarasa produk asapan. Pengukuran nilai $\mathrm{pH}$ dilakukan dengan menggunakan alat pH 210 microprocessor $\mathrm{pH}$ meter. Hasil pengukuran $\mathrm{pH}$ tempurung kelapa dan sabut kelapa dapat dilihat pada Tabel 2. Hasil analisis nilai $\mathrm{pH}$ dalam penelitian ini, masuk dalam kategori nilai $\mathrm{pH}$ dari stnadar kualitas Jepang.

\section{Kadar Asam}

Kadar asam asap cair diketahui dengan menggunakan proses titrasi asam basa. Diketahui bahwa mol $\mathrm{CH}_{3} \mathrm{COOH}=$ mol $\mathrm{NaOH} 1 \mathrm{M}$ sehingga kadar asam (\%) dapat diperoleh. Kadar asam yang diperoleh dalam penelitian ini berkisar antara 2,25-2,29. Perbedaan jumlah kadar asam yang diperoleh, disebabkan karena adanya perbedaan kadar hemiselulosa. Hal ini dijelaskan oleh Apituley dan Darmadji (2013) bahwa asam asetat dan furan mulai 
terbentuk pada suhu pirolisis $260^{\circ} \mathrm{C}$ akibat dari degradasi hemiselulosa. Hasil analisis nilai $\mathrm{pH}$ dalam penelitian ini, masuk dalam kategori nilai $\mathrm{pH}$ dari stnadar kualitas Jepang.

\section{Kadar Fenol}

Kadar fenol pada asap cair tempurung kelapa dan sabut kelapa memiliki perbedaan. Masing-asing kadar fenol pada tempurung kelapa dan sabut kelapa adalah 2,432 dan 2,387. Perbedaan ini diduga disebabkan karena perbedaan kandungan lignin pada tempurung kelapa dan sabut kelapa, sehingga mempengarhui proses pirolisis. Senyawa fenol berperan sebagai donor hidrogen dan efektif dalam jumlah kecil untuk menghambat terjadinya oksidasi pada lemak atau mencegah terjadinya oksidasi lipid dengan menstabilkan radikal bebas dan efektif untuk mencegah terjadinya off flavor (Pszczols, 1995).

\section{KESIMPULAN}

Hasil analisis kandungan kimia dari asap cair tempurung kelapa memiliki berat jenis 1,083 gr/ $\mathrm{cm}^{3}$, keasaman 2,29, kadar asam sebesar 4,628\% dan kadar fenol 2,432\%. Berbeda dengan kandungan kimia dari asap cair sabut kelapa yaitu berat jenis 1,009 $\mathrm{gr} / \mathrm{cm}^{3}$, keasaman 2,25, kadar asam sebesar 3,562\% dan kadar fenol 2,387\%. Hasil analisis kandungan kimia dari asap cair yang dihasilkan bekum sepenuhnya masuk dalam kategori asap cair standar Jepang.

\section{DAFTAR PUSTAKA}

Apituley, D. A. N. dan P. Darmadji. 2013. Daya hambat asap cair kulit batang sagu terhadapkerusakan oksidatif lemak ikan tuna(Thunnus sp) asap.33 (2) : 162-167. Yogyakarta.

Budijanto, S., Hasbullah, R., Prabawati, S., Setyadjit, Sukarno dan Zuraida, I. 2008. Identifikasi dan uji keamanan asap cair tempurung kelapa untuk produk pangan. J.Pascapanen. 5(1), 32-40.

Fikri, M., S.P. Abrina, A. dan Ayu, C.K.F. 2018. Kajian kadar air tempurung kelapa terhadap keasaman produksi asap cair. Jurnal eRUKA Vol (2) 2 : hal 202-207.

Firmansyah. 2004. Penggunaan Kombinasi Serbuk Kayu Jati dan Cangkang Telur Ayam pada Produksi Asap Cair. Skripsi. Fapet-IPB. Bogor. $43 \mathrm{pp}$.

Kailaku, S.I., Syakir, M., Mulyawanti I, dan Syah A. 2017. Antimicrobial activity of coconut shell liquid smoke. IOP Conf. Ser.: Mater. Sci. Eng. 206. doi:10.1088/1757899X/206/1/012 050 .

Kadir, S., Darmadji, P., Hidayat, C, dan Supriyadi. 2010. Fraksinasi dan identifikasi senyawa volatil pada asap cair tempurung kelapa hibrida. Agritech, 30(2): 57-67.

Kasmudjo. 2012. Dasar-dasar pengolahan minyak kayu putih. Yayasan Pembina Fakultas Kehutanan Univesitas Gadjah Mada. Yogyakarta.

Nasir, S., Doni, M., dan Andonie, R. 2008. Pengaruh kondisi operasi pada pembuatan asap cair dari ampas 
tebu dan serbuk gergaji dari kayu kulim. Jurnal Teknik Kimia, 15(4): 8-15.

Nurhayati, T. 2000. Produksi arang dan destilat kayu mangium dan tusam dari tungku kubah. Buletin Penelitian Hasil Hutan 18(3);137-151.

Pszezola, D. E. 1995. Tour highlights produc-tion and uses of smokebased flavors. Liquid smoke a natural aqueous conden-sate of wood smoke provides various advantages in addition to flavors and aroma. J Food Tech. 1, 70-74.
Rasyidta, dan Pari, G. 2015. Pengaruh pemberian arang terhadap pertumbuhan tanaman cabai merah (Capsicum annum). Buletin Penelitian Hasil Hutan, 20(3): 217-229.

Wardhani, I.S. Distribution of chemical compounds of coconut wood (Cocos nucifera L.), Jurnal Ilmu dan Teknologi Kayu Tropis, Vol.2, No.1, 2004.

Yatagai, M. 2001. Utilization of charcoal and wood vinegar in Japan. RDCFPT in Coorporation with JCFA, Bogor. 